\title{
Designing loT Resources to Support Outdoor Play for Children
}

\author{
First Author \\ Department Name \\ Institution/University Name \\ City, State, Country \\ email@email.com
}

\author{
Second Author Name Surname \\ Institution/University Name \\ City, State, Country \\ email@email.com
}

\author{
Third Author Name/Surname \\ Department Name \\ Institution/University Name \\ City, State, Country \\ email@email.com
}

\begin{abstract}
We describe a Research-through-Design (RtD) project that explores the Internet of Things (IoT) as a resource for children's free-play outdoors. Based on initial insights from a design ethnography, we developed four RtD prototypes for social play in different scenarios of use outdoors, including congregating on a street or in a park to play physical games with IoT. We observed these prototypes in use by children in their free play in two community settings, and report on the qualitative analysis of our fieldwork. Findings highlight material qualities that encouraged social and physical play under certain conditions, suggesting social affordances that are central to the success of IoT designs for free-play outdoors. We provide directions for future research that addresses the challenges we faced when deploying IoT with children, contributing new considerations for interaction design with children in outdoor settings and free play contexts.
\end{abstract}

\section{KEYWORDS}

Insert keyword text; Insert keyword text; Insert

\section{INTRODUCTION}

Outdoor play is widely understood to be an important part of childhood, that for many of us, is closely tied to fond memories of the people and places we knew when growing up. Playing outside is about having fun, but is also really good for children's well-being because it provides opportunity for physical, social and personal development $[3,4,8,11,19]$. Despite the many benefits of outdoor play, social commentators in the UK have

Permission to make digital or hard copies of all or part of this work for personal or classroom use is granted without fee provided that copies are not made or distributed for profit or commercial advantage and that copies bear this notice and the full citation on the first page. Copyrights for components of this work owned by others than ACM must be honored. Abstracting with credit is permitted. To copy otherwise, or republish, to post on servers or to redistribute to lists, requires prior specific permission and/or a fee. Request permissions from permissions@acm.org). CHI 2019, May 4-9, 2019, Glasgow, Scotland, UK.

(C) 2019 Copyright is held by the owner/author(s). Publication rights licensed to ACM. ACM ISBN 978-1-4503-5970-2/19/05...\$15.00.

DOI: https://doi.org/10.1145/3290605.XXXXXXX reported a substantial decline in the number of children playing outdoors [15]. Adults are often seen to be gatekeepers to the outdoors and their fears about safety, or own lack of physical activity, can play a major role in determining wither children play outdoors or not [5]. In the UK, research suggests that children from lowersocioeconomic backgrounds are less likely to have access to suitable green spaces and are more likely to engage in 'street play' nearby their home [23]. It has also been argued that children's outdoor play has become more constrained and adult-controlled through a reliance on the protection provided by supervised activity centres and structured activities [14]. The work reported in this paper investigates the potential role of IoT as a resource within active free-play amongst groups of children outdoors. Children are consuming more screen-based media than ever [17] and this is often correlated with a decline in outdoor play. Here we consider wither physical-digital interaction with IoT could incentivise outdoor play through the design of interactive resources that enable new kinds of play experiences.

We build on our previous work [Anom] and an ongoing design ethnography with a community centre in Northern UK that provides activities for children during the school holidays. Throughout this work we have focused on children under the age of nine. This paper reports on exploratory prototyping activities that have seen us designing and iterating physical-digital designs, which try to augment the children's play without detracting from their interaction with each other and the outdoors. By observing and gaining feedback from children and play facilitators across two sites, we have been able to consider challenges, opportunities and social situations in which IoT might support active-free play outdoors.

By reporting on our prototypes and findings, we make a three-fold contribution to the field of Human Computer Interaction (HCI). First, we deliver qualitative case study insights regarding the role of IoT in facilitating active free-play and associated social and physical interactions 
between participating children. Second, we provide lessons for future interaction design by proposing ways of enabling children to configure and control IoT resources. Third, we report on social situations and environmental constraints that promoted and hindered active-free play with our IoT prototypes. We discuss these findings to suggest a broader set of concerns for future $\mathrm{HCI}$ research, beyond designing for play experiences specifically, and instead enabling conditions in which active-free play outdoors can thrive in the first place. Our contributions aim to advance a number of cross-disciplinary discourses, including Interaction Design with Children (IDC), play and game design, and on the role of digital technology in active free play.

\section{BACKGROUND WORK}

To build upon existing work, we draw from HCI and IDC discourses where research has facilitated, mediated and otherwise supported how we might use technology (and relatedly IoT) in outdoor play. These communities are learning about outdoor play by asking three key questions: What type of play can we support? Where can we support children at play [1,2]? And how can we support children in creating their own play [18]? Furthermore, there are many opportunities to push interaction possibilities as we think about the player as a resource in themselves (e.g. $[12,20]$. Throughout this background work authors share a consensus that play should be "heads up" (see [22]). Soute's HUGS are games that reimagine traditional games and play through augmentation and technology but avoid the pitfall of children being fixated by computer screens.

From the outset, our work has been about children playing outdoors in a local community setting. Back et al. [2] is particularly relevant to our inquiry, the authors describe opportunities when designing for close-tohome play with digital technologies that help foster reoccurring play patterns within public spaces and invite players to get back together. These designs are realised further in [2], which looks at supporting play with technology in a school yard. Here digital interactive installations are mixed with more natural materials that provide endless possibilities for open play.

Importantly, we are interested in encouraging creative free play over more passive and prescribed play. Rather than just provide children with complete games, researchers have argued that we should provide platforms for game creation where children are given a starting point but can alter existing mechanics or rules. The RaPIDO platform [21] allows children to change rules and games 'in the wild'. This work was originally written using a textual language for the children's programs. However, authors suggest ModKit and Scratch are more suitable options for future work. This is realised by [18] who present a coding platform for outdoor free play using a graphical user interface for their connected play devices. These authors suggest that we create tools and provide opportunities for children to become their own experience creators. This is also echoed in [9] who use coding building blocks for play with emphasis on movement and measurement to encourage more co-located physical and social play. In contrast [10] found this kind of play was not without risks. Here, digitally enhanced versions were shown to reduce collaborative social interaction and reduced creative thinking when compared with traditional outdoor play resources without technology.

Our prototypes relate to relevant facets of previous work. A variety of work for example has considered different materials for the outdoors [refs], as well as form factors that includes controllers [ref] and worn [13] in a multitude of different ways, around an ankle for example. Like the previous research that advocates appropriation, Oriboo can be programmed to accommodate different games. The range of interactions available are clearly important but there are types of interactions which have not necessarily been applied to outdoor play with children. For example, [16] provides a number of design strategies for working with proxemics. Proxemics is concerned with the interpersonal distance between players. This is appropriate for children's play; games like tag and other games that necessitate being physically close with one another and the proxemics concept helps unpack how we use this in design. Lastly, resources with their materiality and capabilities only provide one part of play. [12] is one author that talks about the players themselves as part of our platform. Albeit a dance game, Yamove! does not force players to over adapt to the technology itself (and be limited by the technology). Yamove! instead allows players to judge the play themselves and in that sense provides more complexity than might ever be programmed. In this sense, we might also think about opportunities to allow players to master and lead play without programming - 
Insert Your Title Here

but through simple interactions like summoning etc. [segura - Larp].

\section{PROTOTYPES}

Rather than create fixed play equipment like [1], in this project we consider IoT resources that children own and take outside themselves. In this way we envisage children using the designs to demarcate and create play spaces in their neighbourhood, or to own individual IoT designs, but use them to interact collectively when they meet up outside with other children. We are principally concerned with active group play outdoors as this has been central to our observations of how the children play at [Cedarwood] [Anom]. An important concern throughout our work has therefore been ensuring our IoT prototypes do not detract from children's interaction with each other and the outdoors. In this way, we are keen to maintain the important benefits of active free play outdoors, but to provide novel resources that can perhaps make outdoor play more exciting.

We are keen for children to take ownership of their play, through IoT designs that can be adapted and customised to suit their individual interests. Eventually we want to provide a set of shareable resources and so each prototype has been envisioned as a kit of parts that children could make and customise themselves, with some help from an adult. Further refinement and testing with children will be required, however we have used laser cut wood, and off-the-shelf materials like copper pipe, that could feasibly form an Instructable or set of low-cost pre-manufactured parts. Relatedly, our prototypes use the micro:bit, which is a cheap and readily available IoT programming platform designed for children.

\section{Play Poles}

The Play Poles (Figure 1) are a set of six moveable poles that have discs on top, coloured on one side and blank on the other. An associated controller has six buttons with colours that match each coloured disc, when you press a button, the matching disc will spin around to reveal the coloured side. If you touch the pole (copper pipe) it will cause the disc to spin around again to show the blank side. There is also a reset button that causes all the discs to spin back around to the blank side. The discs were chosen over, say lights, because they were clearly visible in day time and had also appeared playful in the way they
WOODSTOCK'18, June, 2018, El Paso, Texas USA

spun, or flipped around when you touch the pole. The Play Poles were created using the BBC micro:bit, which allows us to read the capacitance of the copper pipe, as well as communicating with the controller and other Poles through a built-in radio. The disc was attached to a servo so it could spin around.
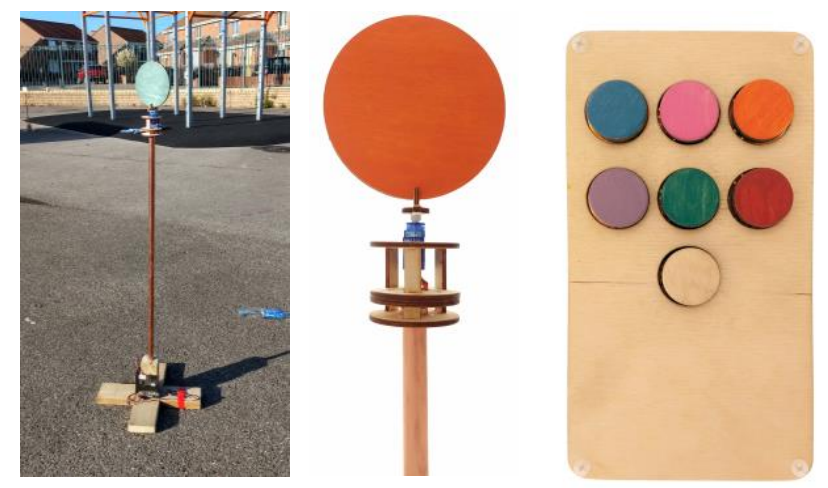

Figure 1. Play Poles: (a) at [Cedarwood], (b) coloured disc detail and (c) controller.

While at [Cedarwood] the children spend much of their time playing group games in the yard, some familiar and others they have made up. This play often involves visual markers, like drawing chalk on the ground and standing behind it, or touching the shed, then the fence, and running back again. One of the children talked about a 'counting wall' on her street that was familiar to her and her friends. The 'counting wall' was a designated place to count in hide and seek. Similarly, another child talked about a telephone exchange box that her and her friends used as a base in various versions of 'tag'. Objects and visual markers situated on the street were commonly shared between children and represent a meeting point for games they enjoyed [Anom]. The Play Poles explored the idea of IoT that children might place on their street, or in a park, in order to demarcate and take ownership of a location by structuring games and play.

The Play Poles could be moved around [Cedarwood] allowing children to add to what was otherwise an empty yard. Building on our own previous work, we kept the interaction open-ended, with a clear function that we felt could be appropriated by the children. An important element of the play we observed was that it evolved and moved-on frequently in response to social conflict or because a new opportunity presented itself [Anom]. We therefore required an easy and quick way of creating interactions 'in the moment'. Initially we explored automatic interactions, but in the end, we decided to use 
a controller, because it would mean children could have direct control over their interactions simply by pressing buttons. In this way, interactions could be structured and invented by them, in play, as rules changed, and new opportunities emerged.

\section{Beacon Boxes}

\section{[Photos tomorrow]}

The Beacon Boxes consist of four matt black boxes (so they could be easily hidden) and a ring of light that approximated how close you were to each box. Sixteen LED lights were mapped to the approximate signal strength giving a representation of proximity. To activate the next box in a sequence you must deactivate the previous box, by holding a button on the top, meaning the boxes are found in sequence. The box could be opened and would reveal a space to hide 'treasure' for other children. Again, the treasure boxes used the BBC micro:bit.

Like preceding prototypes, we see the Beacon Boxes as something the children might own individually, and come together collectively to hide for each other. During our workshops some of the children talked about play that involved hiding and finding things on their street. Eve explains for example how you play 'Hello Neighbour': "Someone is the hello neighbour and they hide three things and other people who aren't the hello neighbour have find them... but the hello neighbour catches them, and they have to be dead." Eve talked about incidental 'green spaces' on her street where she would play 'hello neighbour with her friends.

While at [Cedarwood] we thought the Beacon Boxes would encourage the children to make greater use of the periphery of the yard where there are pockets of bushes, overgrown grassy areas around the side of the building, and large vegetable planters, which were rarely part of the children's play.

\section{Play Watches}

[Do we have any decent photos?]

The Play Watches explored wither IoT worn on a wrist, leg or arm, could be used by the children in active free play outdoors. We imagine children creating their own Play Watch, which would encourage play by 'connecting' with other children (who are also wearing a watch) when they get together outdoors. To make the Play Watches we laser cut parts from plywood that allowed us to attach a Velcro strap, vibrating motor and battery to the micro:bit. Two principal interactions were used with the children. First, the children could signal to each other by pressing either of the two buttons on the micro:bit, which would cause a vibration and one of two symbols to appear on another watch (square or a circle). Second, the children had the ability to either heal or infect other children, depending on the symbol on their micro:bit, type of vibration, and how close they were to other children. Both interactions were seen as a way of extending and enhancing a game of 'tag' through IoT. We cannot emphasize enough, how much the children love 'tag' and we have seen various versions of the game as reported in our previous work [Anom]. The Play Watches are an example of IoT that responds to the proximity of other children.

\section{Play Cans}

[Photos tomorrow]

The Play Cans were an iteration of the Play Poles that retained their basic functionality but offered customisation through additional parts. Here we to experimented with IoT that could be quickly adapted by children both physically and digitally. For example, building on the other prototypes, the Play Cans could be set up as poles that respond to touch and/or respond to the presence of other Play Cans through proximity. The enclosure was a tin can because it would be readily available to children or parents, and the inner workings were supported by a laser-cut structure that could be constructed and snapped into the tin can, by way of a magnet on the base. The Play Cans have a magnet on the bottom, which allows you to connect it to magnetic surfaces, or different hangers, ground spikes and like the previous version, copper poles. There is also a magnet on the top that rotates, allowing you to add a series of different dials and arrows, alongside the original coloured discs. We used a bulldog clip to hold the original coloured discs (as described in Play Poles), again attached with a magnet, meaning the children could add different drawings, images, or anything they found lying around. The use of magnets also meant we could avoid breakages because previously we found the children wanted to twist the top of the Play Poles, meaning they are prone to breaking off at the join between the disc and the servo itself. 
Insert Your Title Here

\section{RESEARCH SITES}

This work reports on an ongoing design ethnography with [Cedarwood] community centre in the North East of England. Initial workshops and observations with [Cedarwood] have been reported previously [Anom] and here we build on this work by reporting on the use of subsequent prototypes. Additionally, to extend our analysis we have included the use of these prototypes by children from a partner site [BeChange] in the South East of England. All research participants and both sites have been pseudo-anonymised. Both community centres provide activities for children during school holidays at which point we have introduced prototypes and left them available for children or play leaders to play with. Play leaders are experienced play professionals who ensure the children get as much as possible from their time together and have been a valuable resource, bringing a wealth of knowledge and experience to the design and use of our prototypes. Within this paper we draw on the experience of play leaders through interviews and in situ discussions. Both sites are concerned with child-led play and understand the value of active free-play alongside more structured activities when appropriate. At [Cedarwood] and [BeChange] the children have an indoor space and an outdoor space. At [Cedarwood] the indoor space consists principally of tables meaning the adjacent yard, which used to be a car park, is central to their play. Surrounding the tarmac at [Cedarwood] are overgrown bushes and a selection of raised planters for growing vegetables. [BeChange] have a large hall that affords running around indoors, as well as a garden consisting of long grass, raised beds and a small child sized shed (the 'den').

\section{RESEARCH THROUGH DESIGN}

Research-through-Design (RtD) 'in the wild' involves designing and making artefacts in response to time spent understanding people, environments and situations, which are relevant to a topic or research question with social significance and/or theoretical potential [27]. Iterative design and making leads to artefacts that hold "values and positions" [6] when designing for this topic and the subsequent use of artefacts 'in the wild' leads to a range of "procedural, pragmatic and conceptual insights" [6], which will inform related design work and further research [7]. In other words, the subsequent deployment of designed artefacts act as a "lens" through
WOODSTOCK'18, June, 2018, El Paso, Texas USA

which to further articulate an 'in the wild' setting and related research questions [25]. Our RtD inquiry has involved design, making and adapting lo-fi working prototypes in response to suggestions made by the children, as well as our own observations and experiences. Sometimes we adapted prototypes by reprogramming them during our engagements, and at other times we made more significant iterations between engagements. The prototypes were played with by the children and play leaders, as part of their time at [Cedarwood] and [BeChange], giving us the opportunity to experiment and learn about the role of IoT in this play setting. A motivating factor throughout our iterative design engagements was ensuring the children were enjoying themselves and their time together as a group, it was after all their school holidays.

\section{DESIGNING IOT FOR CHILDREN'S OUTDOOR PLAY}

A practical summary of our fieldwork approach.

We now present vignettes and qualitative insights regarding the use of these prototypes at both [Cedarwood] and [BeChange]. Our vignettes unpack the way in which our prototypes became a resource in active-free play, social qualities like familiarity and leadership that led them to being used, social qualities that did not, like disputes, and the role of play leaders in enabling active free-play, along with further challenges.

\section{Spontaneously Motivating Active Free-Play}

The children at [Cedarwood] commonly start the day with indoor activities, but after an hour or two, become restless and benefit from getting outside to burn off energy. It was during this time we introduced the Play Poles, by setting them up in the yard, in two parallel rows of three. Following a brief introduction, we left the Play Poles with the children and play leaders. Initial interactions involved a child having the controller, pushing buttons and watching as others ran to touch poles that were currently flipped around (what became known as "catching all the targets"). Play began quite orderly until one child realized that you could push as many buttons as you like at the same time. Soon the children were running around, jumping and sidestepping between the poles, waving their arms and grabbing active poles to flip the coloured disks back around. A combination of the fresh air, open space and excess energy led them to engage excitedly with the Play 
Poles. The facilitator started 'egging them on' by shouting colours as they flipped around, and the children responded with equal enthusiasm. The children were running around together, laughing, shouting things like, "go, go go" or "I got it" and working together to direct others to poles that were still active, by shouting colours, and inciting urgency. They were clearly having fun, laughing if they went for the same pole, or at the silly and playful ways that other children grabbed the poles. In a notable moment of hilarity, [Dan] activated a pole, and then reset it, just before [Jill] could reach it. [Dan] was a bit of a joker and revelled in the laughter of the other children, occasionally repeating the same intervention when people were least expecting it.

In this case, the Play Poles required little prior structure or explanation to engage the children actively, with pushing buttons, flipping discs and running after them being an evident feature of their design and interaction. Though the children were playing freely together, this play was further incentivized by play leaders, who have been frequently observed inciting playfulness with our prototypes, in this case, by encouraging the children to go a bit faster. This unstructured running around was at times frantic and messy but was viewed positively by play leaders as a way for the children to release their energy in an unprescribed way. Subsequently, two play leaders described their surprise at how active [Cole] was: "I know [Cole] doesn't like running, but he got involved there without being told to get involved, or asked to get involved, and he just went and ran, which it's quite an achievement for [Cole], because [Cole] doesn't have to run you won't run. It's getting them all involved and it's exercise." In this case, unstructured running around can be willingly and spontaneously motived by IoT, without negative connotations commonly associated with 'mandatory exercise'.

In related observations with the Play Watches, with almost no introduction or encouragement children have been seen running spontaneously away from each other. Four children $(\mathrm{j}, \mathrm{s}, \mathrm{g}, \mathrm{x})$ [temp] especially enjoyed playing their own versions of tag which encouraged changing rules. This play was typical of play at [BeChange] where play was theatrical, often spontaneous (and sometimes rehearsed), energetic and yet at times, relaxed. Notably it was almost conflict free with only a minor upset after a child hurt their leg. In these games, children began by planning and took time to ensure the game was set up properly. Children placed a wrist band in a bucket (one of several traditional play resources) to heal players. They instructed, "keep it in the bucket - just in case...". In these moments, children were willing to help set up play, offers of, "I'll help / you help" were common, while children also showing direction and patience, "we are going to do the game, but we are going to wait for [j]" [g]. The pace would then heighten, followed with posturing and anticipation where children declared what would happen next, "I'm warning yaaa" [g], and "are you all ready?", "[s] are you ready?". Play then almost always started spontaneously. Children would feign movement to prompt another, call each other out, or begin a quick sprint. Children meet the start with screaming and repeated taunts, "[j] is on the run [...]" [g], "She's coming. Lets' go", "ooh oh / New skill!", and "I can destroy you all - just by coming near you" [g].

The games continued with this spontaneity; children chose in the moment where to run and hide, and quickly identified the bucket as a base, "Quick to the station" and later in this same place, "You can't get me if I stay near a station". They also guided fair play, "[g] you're not allowed to put it up your shirt" and kept play within the main boundaries of the garden, "you're not allowed to go down there" [j]. They often returned to the shed in the garden, which was an important base, but one where it could be easy to be caught, "I've got you cornered" [g] says to [s]". In one decisive bit of play, a child barricades themselves in the shed behind the door. The chasing play reaches out to tag the child by placing their wrist near the only exposed body part - an arm blocking the door. Caught, they respond, "you got me" / "you're a cheat" [j], before pleading "rescue me" to another. They are quickly rescued and joined by the previously injured girl who is now happily running with them. These vignettes are typical of play that has ever changing rules with children happy to alternate between chasing, pursuing and resting at their adopted bases.

\section{IoT as a Resource}

A group of children at [Cedarwood] settled on a game that became known as the "colour game". To play the game, you choose a pole to stand beside. One person is given the controller and they must turn around and randomly push a button. If the pole you are standing beside flips around, then you are out of the game and must stand to one side. The remaining players then choose another pole and the game continues until you have one player remaining, who is the winner. 
Insert Your Title Here

On paper the colour game seems very simple, however it came alive at the hands of the children, who imbued it with energy, enthusiasm and light-hearted banter. While picking a pole, the children never stood in an orderly manner, but created play by running excitedly between the poles, skipping and jumping, as if trying to decide which one will be safe this time around, of course, in truth it is 'pot luck'. When a player is standing at a pole, but changes their mind and moves quickly to another, the group laughs at how lucky they are to still be in the game. If a player is out, everyone responds in some way: "nooo!", or "aww", or "aww Lilly is out", or "I am so lucky!". And, when waiting at a pole, there is a degree of suspense that is heightened by the children eventually standing still, looking around and watching other players.

Both the Play Poles and the rules of the colour game contributed to the experience, but active free-play was evident in the accompanying gestures and running commentaries that were central to the children's social interaction. IoT as a resource, can enable children to create novel kinds of play, but this need not distract from their own creativity and interaction with each other. The Play Poles are an IoT resource and not a game, or play. Rather, they merely provide novel opportunities that children might appropriate.

\section{Familiarity and Ownership}

We had not anticipated one game would be repeated so many times, but the colour game became well-rehearsed, and was shared between those children who had been there from the outset. One play leader described the situation: "This is our game now. They've created the game and so are going to play because they know exactly how to do it, nice to see actually". Like an 'inside joke' these children knew how they were going to play together, because the game had a rhythm and structure that they could implement and share as a group. Though we have always invisioned IoT that affords variety, in this case, we see familiarity and ownership as key charateristics sustaining play with the Play Poles.

\section{Resolving Conflict with loT}

Throughout or time at [Cedarwood] we continue to encounter conflict between the children that can be a barrier to sustained outdoor play. One afternoon at [Cedarwood], [Zidan] had gotten upset because he wanted to play "his game" and so we helped him by rounding up other children and introducing the game.
WOODSTOCK'18, June, 2018, El Paso, Texas USA

The game was an extension of 'tag' with the Play Poles acting as a "safe space" in which another player could not tag you. In this case, one of the researchers had the controller and changed the "safe space" at regular intervals by pressing buttons and flipping different discs to show which "safe space" was active. Despite initial excitement over the game, it soon led to conflict because [Cole] felt he was getting "picked on" by the other children. [Cole] had been happy playing the colour game, but here, he was singled out for being slower and could not 'tag' any of the other children, who were older and much faster than him.

We have discussed such disputes with play leaders, who see IoT as a way of augmenting outdoor games that often lead to conflict. A point of reference for play leaders is 'goal-line technology', which is an electronic aid used to determine if a goal has been scored in football. Based on the notion of goal-line technology one play leader experimented with a game of rounders, only this time the bases were Play Poles that you touch in order to clearly show you have 'hit base'. The rationale was that while the children enjoy the game, it is marred by, "[...] arguments, constant arguments. I was there before you even got to it. They throw the bat. Go away in huffs, you name it." [Denise]. Though we want to support independent outdoor play, we have come to see the important role of play leaders in supporting children, who may for example, need support resolving conflict in order to get the most from their time with other children.

\section{Leadership}

We have found a range of social situations that support outdoor play. Leaders are children who take responsibility for creating and sharing games with other children and we have found them to be essential in having groups of children play with our prototypes on their own terms. [Eve] for example, exudes confidence and is enthusiastic about inventing play. Though she is sometimes bossy, she motivates the other children, bringing them together so they can play outdoor games.

One afternoon, the children were given the Play Cans and proximity code that meant an arrow twitched when they got close to each other. The children were 'messing around' with the prototypes when two friends realised the magnets on the base of a Play Can would stick to the [Play Lab]. Often children will spend time exploring how they might use our prototypes, before moving on and playing something else, or settling on something to play. 
Watching the two friends, [Eve] excitedly announced to the group, while jumping up and down, "I know a game we can play on the wall". She continued, "Basically, what you have to do is move [the Play Can] about and then, whoever keeps it moving for the longest wins". [Eve] began demonstrating the game (Error! Reference source not found.), but had to raise her voice because no one was listening: "Can I just say what it is... we all start at the same place and then we move it away and then whoever keeps moving, or whoever moves for the longest wins." [Eve] perseveres, "everybody put yours in the middle! [...] put it in the middle so we can play the game", and finally the other children gather around to play the game (Figure 2).
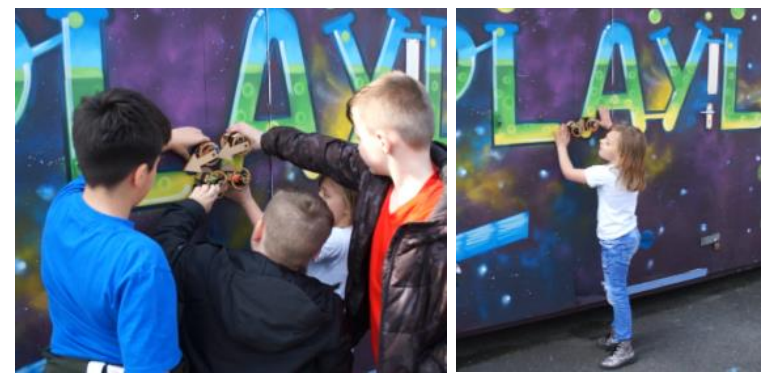

Figure 2. Eve demonstrating her game with the Play Cans

\section{Opportunities to Lead}

When we do not have a leader like [Eve], we find the children benefit from some support from play leaders, especially when playing group games. In contrast to [Eve], [Cole] finds it difficult to be assertive and frequently 'gets upset' while playing at [Cedarwood]. During the colour game, the player with the controller tends to direct the other children and structures the game by pointing and repeating key phrases, like "change", "ok, everyone pick a colour", "everyone ready", and "no one there". Having the controller gave [Cole] the opportunity to lead the other children by putting him in a position of control. When asked wither a controller, or automation was better one play leader explained: "If you've got kids like [Cole] that are able to figure things out, control the game, or even take a lead, this naturally encourages leadership in kids, which you have to do, and if you go automated it doesn't really have the same effect."

These vignettes highlight the importance of helping children develop social skills that enable them to create their own play outdoors. A central point of control means IoT can provide children with the opportunity to lead, perhaps building confidence in future play encounters. That being said, having the controller was so popular, play leaders had to help negotiate turn taking.

\section{Cooperative Play in the Boundaries}

When playing with the Beacon Boxes the children shared and cooperated by following alongside the player holding the light meter. In the following vignettes the children had successfully found three Beacon Boxes. The children were checking all the boxes by holding down the buttons (Figure 3), but realised there is one still active. [Cole] deduces that, "None of them are the right one!" and so [Eve] anounces excitedly, "Where is the other one!?" This causes the children to run around together, with [Dan] holding the light meter and the others following alongside. Reaching the corner of the Tarmac, near some bushes, [Eve] notices a change on the light meter and announces, "We are nearly there! look it is full!" (Figure 3). Her sister, [Jill] responds, "Where is it?". They look around the bushes, knowing it is there somewere, but are not able to see it. To have a closer look the children clamber on the bushes. [Eve] says, "we are so close", at which point [Ben], who was holding the light meter repeats, "I'm so close... oh my goodness". [Cole] spots an opening in the bushes and climbs on for a closer look, "I know were it is, it's got to be inside here". Shortly after, [Cole] anounces, "I found it!!" and holds the box up proudly. The rest of the children gather around excitedly: "Let me see it!"; "No, press the button, press the button!?". Excitedly, [Eve] announces "Can I hide them now? Can I hide them now?" In contrast to other prototypes, finding the Beacon Boxes became a cooperative pursuit that brought children together through a shared goal. Like the Play Poles, the children spurred each other on, in this case through a shared objective.
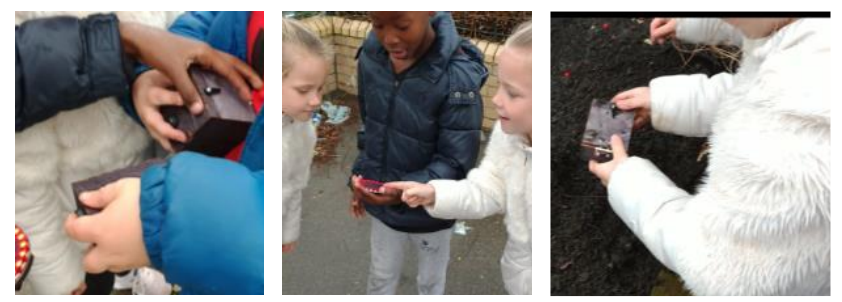

Figure 3. Playing with the Beacon Boxes

\section{Getting Dirty}

Having played for a while, taking turns hiding the Beacon Boxes, the children were in an area of the garden with large vegetable planters. [Ben] had been boasting to the other children that he had found the best hiding spot and 
Insert Your Title Here

the other children were never going to find the last box. [Cole] asks, "is it somewhere around here?" and [Ben] confirms while laughing proudly, "This is going to be hard!". After looking for some time, [Cole] notices a patch of soil that looked like it had been turned over. He told the others, "everyone, I need help digging". One of the researchers asks, surprised, "did you actually burry it!?". [Cole] responds, "how am I supposed to get it if I can't dig?". Determined to get the box, and holding the light meter, which was conveniently flat and round, he starts digging with it, using it to find the box. "Ahh, there it is..." [Eve] states, as the other children laugh while she pulls it out of the soil. The light meter only showed a general vicinity and this caused excitement because the children knew it was close, but couldn't see it. The children then had to explore, delve into the bushes and eventually, dig. Though a modest example, we show that IoT can become a resource for outdoor play, that encourages engagement with nature, even when limited to verges, over grown bushes and planters.

\section{Challenges}

In this section we consider some challenges we encountered while using our prototypes with the children. While digging up the Beacon Boxes and despite our best intentions and our interest in having the children make full use of the space, the play leaders were not best pleased to discover that the cuffs of the children's jackets were dirty with soil. The sisters, [Eve] and [Jill] got particularly dirty and a play leader, who was related and knew the children, gave them in trouble: "the colour of that coat are you joking me? [...] Your mother will go absolutely mad". In response they explained, "but... we were finding it" and "but... [Ben] said he buried it and we had to find it". Our intention was to explore how we might support playing and considered their broader engagement with the environment to be a positive intervention. Yet, on a number of occasions like this, the children encountered barriers in their practical interaction with the outdoors. We apologized and took responsibility for the "state" in which the children had found themselves.

In another instance, we took the children to an area outside of [Cedarwood] to explore how they might use the Play Cans. Unfortunately, shortly after having the children set them up, one child became visibly upset and embarrassed because he had gotten "dog poo" on his new white trainers. One of our researchers quickly became
WOODSTOCK'18, June, 2018, El Paso, Texas USA

concerned, because within the long grass was lurking many more, potentially smelly accidents. When asked wither we should return to the confines of [Cedarwood], the children quickly reached a "yes!" consensus. Throughout the local area, in fact, we have found litter and glass and, humbling though it is, dealing with these broader issues may be a more fundamental concern to achieving sustained outdoor play and building the confidence of both parents and children.

Our prototypes were mostly robust enough to survive until the end of our engagements and the light meter still worked despite being used as a shovel. That being said, the Play Poles appeared fragile and this meant the children were frequently told to "be careful with them instruments" or "watch, don't drop that" or "don't touch the top". This was despite continuous reassurance that we wanted them to be used as the children saw fit. IoT designs should not only be robust, but look and feel robust and suitable for the outdoors. This would give play leaders and parents/guardians the confidence to let children play freely with them. Concerns about the children dropping our prototypes was common and this was not helped by the fragile sounding 'thud' they made when they hit the ground. One could imagine foam housings or rubberised materials that look and feel protected. The same is true of cost, play leaders called the designs "instruments" and referred to their potential monetary value. Low cost IoT designs would be important because they may get lost, or parents/guardians might worry about them being lost and thus restrict their use outdoors in the first place.

\section{DISCUSSION}

We have reported on our RtD project and five exploratory prototypes that have allowed us to derive qualitative insights relevant to the design of IoT for active free-play outdoors. The prototypes derive from previous work [Anom] and contribute to a scenario where children take IoT outside to create play experiences in places that are familiar and accessible to them. Wither this is on their street, within 'incidental' green spaces, trees and bushes around their neighborhood, or in the park itself. In our next stage of work, we aim to deploy iterations of these designs so children can make and use them in places familiar to them. This stage of work has however allowed us to 
develop our designs further in light of our observations and feedback from children and play leaders.

\section{The Design of IoT when Facilitating Active-Free Play}

This paper has presented a range of qualitative case study insights relating to the role of IoT in facilitating active free-play and associated social and physical interactions between participating children. We have shown that simple, direct functions can lead children to engage in active free-play together. The dynamics of the play we witnessed include running around without rules (Play Poles), running around because of the rules (Play Watches), through to cooperative play involving the Beacon Boxes. While some of the games had rules (i.e. Colour Game) and the prototypes provide novel functionality, play was generated by the children's enthusiasm and creativity, which was evident in their spontaneous gestures, ongoing cometary and hilarity. Both the Play Poles and the Play Watches led children to run around without detracting from their interaction with each other. And, we suggest the Beacon Boxes provided a degree of specificity, whilst leaving the interaction open enough for the children to interact with the outdoor environment. In the cases presented, we propose that IoT with the right balance of control and structure can support important characteristics of outdoor play, like physical, social and personal development $[4,19,24,26]$ and suggest further research is required.

\section{Creating and Controlling loT Interactions}

Based on our prototypes and fieldwork we consider ways of enabling children to configure and control IoT resources. We have been building prototypes that can be adapted while with the children. This process has at times slowed the children down because we cannot implement changes quickly enough, before the children move on, or lose interest. We see the value of programming for outdoor play [18] but in the cases presented, the children have not shown an interest in programming. In previous work we have reported the way play changes and adapts fluidly according to the children's creativity and emerging opportunities [Anom]. Exploring other kinds of control, or giving the children parameters that can be changed instantly while playing with IoT, could be more appropriate when enabling such changes 'in the moment'.
The Play Poles for example, provided direct control via a controller that flipped particular discs around. This gave the children space to create a playful dynamic that was not overly directed, rigid, or prescribed. Ultimately, they could create their own interactions and therefore play dynamics, by pressing buttons, while allowing social interactions and negotiations to flourish according to the interests of the children. [Dan] revelled in the laughter of the other children, laughter he had created while using the controller. Relatedly, [Cole] was able to direct and lead the children while playing the Colour Game. This approach is deceptively simple, but technology does not need to be fully automated, and could instead provide simple mechanisms that give control and flexibility in the moment'. For example, did we need to provide the children with a light metre that sensed the Beacon Boxes? Or could we have just given another child the ability to change and control the light meter according to were they had hidden the Beacon Boxes? The children's imagination is such that sensing and controlling interactions may not may not be necessary, and could even restrain play because it is not creatively malleable.

\section{Challenges and Barriers to Outdoor Play with IoT}

Our prototypes only address part of a wider set of measures that could enable outdoor play more frequently. We have found community centres to be essential in encouraging and enabling children to experience outdoor play. [Cedarwood] and [BeChange] enable children to spend time with others in a safe and friendly environment that provides freedom, alongside a degree of facilitation (when necessary) that we have found to support meaningful play interactions between children in the local community. Given contemporary concerns about 'stranger danger', litter, dog poo, and increased traffic on the roads, [Cedarwood] and [BeChange] may be the best we can offer some children, providing an environment in which parents can feel confident their children are safe.

There is a broader need to publicize and demonstrate the value of 'Playing Out', such that children can be encouraged and supported by adults. In the case of getting a dirty jacket, it might be as simple as wearing appropriate clothing and therefore giving permission to get dirty. Relatedly, some children may happily play around dog poo, yet it does little to encourage, or support perceptions of 'Playing Out' in the local area. With regards the Beacon Boxes, there are obvious safety 
Insert Your Title Here

concerns when we extend this notion beyond the confines of [Cedarwood] and into an urban environment were there could be dangerous objects in the bushes. Further research should position IoT within the homes, streets and estates of children, thus locating them within the realities of 'Playing Out' for children and parents alike. Future work should move beyond merely thinking about IoT for play and instead IoT that enables play. Wither this is supporting environmental barriers, enabling children to negotiate play outdoors on their own terms, or providing ways for communities to intervene and create their own play spaces.

\section{CONCLUSION}

In this paper we...

\section{REFERENCES}

\section{[Still to update formatting/style etc.]}

1. Jon Back, Caspar Heeffer, Susan Paget, Andreas Rau, Eva Lotta Sallnäs Pysander, and Annika Waern. 2016. Designing for children's outdoor play. DIS 2016 - Proceedings of the 2016 ACM Conference on Designing Interactive Systems: Fuse: 28-38. https://doi.org/10.1145/2901790.2901875

2. Jon Back, Laia Turmo Vidal, Annika Waern, Susan Paget, and Eva Lotta Sallnäs Pysander. 2018. Playing close to home: Interaction and emerging play in outdoor play installations. In Conference on Human Factors in Computing Systems Proceedings. https://doi.org/10.1145/3173574.3173730

3. Colin Boreham and Chris Riddoch. 2001. The physical activity, fitness and health of children. Journal of Sports Sciences 19, 12: 915-929.

https://doi.org/10.1080/026404101317108426

4. Hillary L. Burdette, Robert C. Whitaker, and Stephen R. Daniels. 2004. Parental Report of Outdoor Playtime as a Measure of Physical Activity in Preschool-aged Children. Archives of Pediatrics and Adolescent Medicine. https://doi.org/10.1001/archpedi.158.4.353

5. Karla I. Galaviz, Deena Zytnick, Michelle C. Kegler, and Solveig A. Cunningham. 2016. Parental perception of neighborhood safety and children's physical activity. Journal of Physical Activity and Health 13, 10: 1110-1116. https://doi.org/10.1123/jpah.2015-0557

6. Bill Gaver and John Bowers. 2012. Annotated portfolios. Interactions. https://doi.org/10.1145/2212877.2212889

7. William Gaver. 2012. What should we expect from research through design? In Conference on Human Factors in Computing Systems - Proceedings. https://doi.org/10.1145/2207676.2208538

8. Angela Hanscom. 2016. Balanced and Barefoot: How Unrestricted Outdoor Play Makes for Strong, Confident, and Capable Children. . New Harbinger, UK.

9. Tom Hitron, Itamar Apelblat, Iddo Wald, Eitan Moriano, Andrey Grishko, Idan David, Avihay Bar, and Oren Zuckerman. 2017. Scratch nodes: Coding outdoor play experiences to enhance social-physical interaction. In $I D C$ 2017 - Proceedings of the 2017 ACM Conference on Interaction Design and Children.
WOODSTOCK'18, June, 2018, El Paso, Texas USA

https://doi.org/10.1145/3078072.3084331

10. Tom Hitron, Andrey Grishko, Idan David, Iddo Yehoshua Wald, Oren Zuckerman, Netta Ofer, and Hadas Erel. 2018. Digital Outdoor play: Benefits and risks from an interaction design perspective. In Conference on Human Factors in Computing Systems - Proceedings. https://doi.org/10.1145/3173574.3173858

11. J. Howard and K. Mcinnes. 2013. The impact of children's perception of an activity as play rather than not play on emotional well-being. Child: Care, Health and Development 39, 5: 737-742. https://doi.org/10.1111/j.13652214.2012.01405.x

12. Katherine Isbister. 2012. How to stop being a buzzkill. 1 . https://doi.org/10.1145/2371664.2371666

13. Elena Márquez Segura, Annika Waern, Jin Moen, and Carolina Johansson. 2013. The design space of body games: Technological, physical, and social design. In Conference on Human Factors in Computing Systems - Proceedings. https://doi.org/10.1145/2470654.2466461

14. JOHN H MCKENDRICK, MICHAEL G BRADFORD, and ANNA V FIELDER. 2000. Kid Customer?: Commercialization of Playspace and the Commodification of Childhood. Childhood 7, 3: 295-314.

https://doi.org/10.1177/0907568200007003004

15. Stephen Moss. 2012. Natural Childhood. Swindon, UK. Retrieved from

https://www.nationaltrust.org.uk/documents/read-ournatural-childhood-report.pdf

16. Florian Floyd Mueller, Sophie Stellmach, Saul Greenberg, Andreas Dippon, Susanne Boll, Jayden Garner, Rohit Khot, Amani Naseem, and David Altimira. 2014. Proxemics play: Understanding proxemics for designing digital play experiences. In Proceedings of the Conference on Designing Interactive Systems: Processes, Practices, Methods, and Techniques, DIS. https://doi.org/10.1145/2598510.2598532

17. OfCom. 2013. Children and Parents: Media Use and Attitudes. Ofcom, October: 220. Retrieved from http://stakeholders.ofcom.org.uk/binaries/research/medialiteracy/october-2013/research070ct2013.pdf

18. Netta Ofer, Idan David, Hadas Erel, and Oren Zuckerman. 2019. Coding for Outdoor Play: A Coding Platform for Children to Invent and Enhance Outdoor Play Experiences. In Proceedings of the 2019 CHI Conference on Human Factors in Computing Systems (CHI '19), 164:1--164:12. https://doi.org/10.1145/3290605.3300394

19. Caterina Pesce, Ilaria Masci, Rosalba Marchetti, Spyridoula Vazou, Arja Sääkslahti, and Phillip D. Tomporowski. 2016. Deliberate play and preparation jointly benefit motor and cognitive development: Mediated and moderated effects. Frontiers in Psychology 7, MAR. https://doi.org/10.3389/fpsyg.2016.00349

20. Elena Márquez Segura, James Fey, Ella Dagan, Samvid Niravbhai Jhaveri, Jared Pettitt, Miguel Flores, and Katherine Isbister. 2018. Designing future social wearables with live action role play (larp) designers. In Conference on Human Factors in Computing Systems - Proceedings. https://doi.org/10.1145/3173574.3174036

21. Iris Soute, Susanne Lagerström, and Panos Markopoulos. 2013. Rapid prototyping of outdoor games for children in an iterative design process. In ACM International Conference Proceeding Series. https://doi.org/10.1145/2485760.2485779

22. Iris Soute, Panos Markopoulos, and Remco Magielse. 2010. Head Up Games: Combining the best of both worlds by merging traditional and digital play. Personal and Ubiquitous Computing 14, 5: 435-444. https://doi.org/10.1007/s00779-009-0265-0 
Remove headers \& page numbers in the footers from your final version

23. Liz Sutton. 2008. The State of Play: Disadvantage, Play and Children's Well-Being. Social Policy and Society. https://doi.org/10.1017/s147474640800448x

24. Jenny Veitch, Sarah Bagley, Kylie Ball, and Jo Salmon. 2006. Where do children usually play? A qualitative study of parents' perceptions of influences on children's active freeplay. Health and Place 12, 4: 383-393.

https://doi.org/10.1016/j.healthplace.2005.02.009

25. Jayne Wallace, Anja Thieme, Gavin Wood, Guy Schofield, and Patrick Olivier. 2012. Enabling self, intimacy and a sense of home in dementia: An enquiry into design in a hospital setting. In Conference on Human Factors in Computing Systems - Proceedings.

https://doi.org/10.1145/2207676.2208654

26. Helen Woolley. 2007. Where do the children play? How

policies can influence practice. Proceedings of the Institution of Civil Engineers: Municipal Engineer 160, 2: 89-95. https://doi.org/10.1680/muen.2007.160.2.89

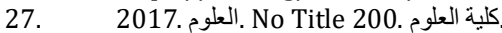

